\title{
INFLUÊNCIA DOS RESÍDUOS DA POLUIÇÃO ATMOSFÉRICA NA SAÚDE RESPIRATÓRIO E NO MEIO AMBIENTE NO PONTAL DO PARANAPANEMA
}

Danillo Nascimento Vicente, Fabiola de Azevedo Mello, Renata Calciolari Rossi e Silva.

Universidade do oeste Paulista - UNOESTE, Mestrado em Meio Ambiente e Desenvolvimento Regional - MMADRE, Presidente Prudente, SP. E-mail: danillonv@gmail.com

\section{RESUMO}

A poluição atmosférica urbana vem sendo um dos maiores problemas que assolam a sociedade. Com o aumento das emissões atmosféricas nas últimas décadas, são notáveis os impactos causados pela poluição atmosférica nas comunidades e no meio ambiente, que são afetados negativamente de modo constante pelos níveis elevados de poluição do ar.

Palavras-chave: Poluição do ar. Meio Ambiente. Doenças Respiratórias. Resíduos industriais.

\section{INFLUENCE OF AIR POLLUTION RESIDUES IN RESPIRATORY HEALTH AND ENVIRONMENTAL IN PONTAL DO PARANAPANEMA}

\begin{abstract}
Urban air pollution has been one of the biggest problems plaguing society. With the increase in air emissions in recent decades are remarkable impacts of air pollution on communities and the environment, which are negatively affected steadily by high levels of air pollution.
\end{abstract}

Keywords: Air pollution. Environment. Respiratory diseases. industrial waste. 


\section{INTRODUÇÃO}

A poluição atmosférica urbana vem sendo um dos maiores problemas que assolam a sociedade (CUISSE, 2014). Com o aumento das emissões atmosféricas nas últimas décadas, são notáveis os impactos causados pela poluição atmosférica nas comunidades e no meio ambiente, que são afetados negativamente de modo constante pelos níveis elevados de poluição do ar (PROENÇA MDGL, 2010).

No Pontal do Paranapanema existem vários fatores que contribuem para essa poluição, pode-se destacar o aumento da frota de veículos constatada em Presidente Prudente (Plano de Mobilidade Urbana de Pres. Prudente, 2014), outro fator que se deve considerar é a quantidade de olarias para fabricação de telhas e tijolos que estão inseridas no Pontal do Paranapanema (BENTO MHS, 2012), a falta de locais apropriados para destinação dos resíduos sólidos ainda é um grave problema enfrentado pelo Pontal do Paranapanema (CETESB, 2015) e apesar de proibida, a queima da cana ainda é realizada em algumas áreas do Pontal do Paranapanema (CARVALHO JUNIOR, 2013).

Devido à grande área de contato entre a superfície do sistema respiratório e o meio ambiente, a qualidade do ar interfere diretamente na saúde respiratória (ARBEX, 2012). Para o Brasil, estima que a poluição atmosférica possa causar cerca de 20 mil óbitos/ano, valor cinco vezes superior ao número de óbitos estimado pelo tabagismo ambiental/passivo, e 10,7 mil óbitos/ano decorrentes da poluição do ar em ambientes internos (OMS, 2009).

\section{METODOLOGIA}

O caminho metodológico utilizado nesse trabalho foi por meio de pesquisas bibliográficas através das bases de dados Scielo, Google Acadêmico, dissertações de mestrado e teses de doutorado, utilizando os filtros poluição do ar, meio ambiente, doenças respiratórias e resíduos industriais. Sendo considerados diversos estudos que analisaram os impactos da poluição atmosférica na saúde humana.

\section{REVISÃO DA LITERATURA \\ Poluição Atmosférica}

A poluição atmosférica urbana vem sendo um dos maiores problemas que assolam a sociedade, não só dos países industrializados, mas também daqueles em desenvolvimento (CUISSE, 2014). Com o aumento das emissões atmosféricas nas últimas décadas, são notáveis os impactos causados pela poluição do ar nas comunidades e no meio ambiente, que são afetados negativamente de modo constante pelos níveis elevados de poluição do ar, visto que a qualidade do ar é diretamente influenciada pela distribuição de emissões veiculares e industriais, bem como a intensidade revela-se de crucial importância para estudo destas emissões (CUISSE, 2014).

Conforme a Resolução $\mathrm{n}^{\circ} 3$ de 28/06/1990 do Conselho Nacional do Meio Ambiente (CONAMA, 2012), considera-se poluente atmosférico "qualquer forma de matéria ou energia com intensidade e em quantidade, concentração, tempo ou características em desacordo com os níveis estabelecidos, e que tornem ou possam tornar o ar impróprio, nocivo ou ofensivo à saúde, inconveniente ao bem-estar publico, danoso aos materiais, à fauna e à flora ou prejudicial à segurança, ao uso e ao gozo da propriedade e às atividades normais da comunidade" (FERREIRA, 2011).

Existem evidências de que a queima de biomassa contribui significantemente para a liberação de gases tóxicos e material particulado (MP) para a atmosfera em todo o mundo, expondo milhões de pessoas todos os anos. (FERREIRA, 2011). 
Sendo assim, o interesse mundial em substituir combustíveis fósseis por biocombustíveis tem gerado um aumento significativo na produção canavieira, e o Brasil dispara no ranking, sendo classificado como o maior produtor de cana-de-açúcar do mundo (FERREIRA, 2011).

\section{EFEITOS DOS RESÍDUOS PROVENIENTES DA POLUIÇÃO ATMOSFÉRICA CAUSADO POR VEÍCULOS AUTOMOTORES NA SAÚDE HUMANA E MEIO AMBIENTE}

Entre as diversas formas de degradação ambiental, a poluição do ar é uma das que mais causam prejuízos à população, afetando a saúde humana, os ecossistemas e o patrimônio histórico cultural, assim como o clima (BENTO, 2012).

As fontes veiculares têm tido uma participação acentuada na degradação da qualidade do ar atmosférico, as emissões causadas por veículos automotores carregam uma grande variedade de substâncias tóxicas, as quais quando em contato com o sistema respiratório, podem ter os mais diversos efeitos negativos sobre a saúde. Essas emissões, devido ao processo de combustão e queima incompleta do combustível, são compostas de gases como: óxido de carbono (CO e $\mathrm{CO} 2$ ), óxido de nitrogênio (NOx), hidrocarbonetos $(\mathrm{HC})$, entre os quais estão alguns considerados cancerígenos, óxido de enxofre (SOx), e partículas inaláveis (MP10) (DRUMM,2014).

O trânsito de veículos é um grande colaborador nas emissões de contaminantes, conforme relatório da Mercedes-Benz (1989), os efeitos dos produtos da combustão incompleta de motores diesel e gasolina, e de outros produtos indesejáveis atuam sobre o homem e o meio ambiente, variando desde a irritação dos olhos, pele e vias respiratórias, até a morte. Também ocorre a destruição de densas camadas de vegetação mais próximas às fontes de emissão (DRUMM,2014).

Alguns combustíveis fósseis, quando queimados, lançam na atmosfera óxido de enxofre e de nitrogênio, e estes são transformados em ácido sulfúrico e nítrico, e/ou convertidos em aerossóis de sulfato e nitrato. Tais compostos retornam à Terra na forma de chuva ácida, e além de prejudicarem os seres vivos, destroem obras de valor artístico (esculturas e construções), implicando também no regime hidrológico das águas continentais e marinhas. $O$ ar poluído, normalmente nas cidades e próximo às áreas industriais, causa irritação nas mucosas do aparelho respiratório, tosse, mal-estar geral, irritações oculares, envenenamento e morte. Provoca o aparecimento da asma, bronquite, enfisema pulmonar, doenças alérgicas e câncer nas vias respiratórias. A cada ano, o mundo recebe somente de veículos automotores, cerca de 80 milhões de toneladas de monóxido de carbono (CO) na atmosfera (DRUMM,2014).

\section{AGENTES CAUSADORES DA POLUIÇÃO ATMOSFÉRICA INSERIDOS NO PONTAL DO PARANAPANEMA.}

Entre os diversos agentes causadores da poluição atmosférica inseridos no Pontal do Paranapanema pode-se destacar o aumento da frota de veículos constatada em Presidente Prudente, maior cidade e com maior concentração da frota de veículos da região.

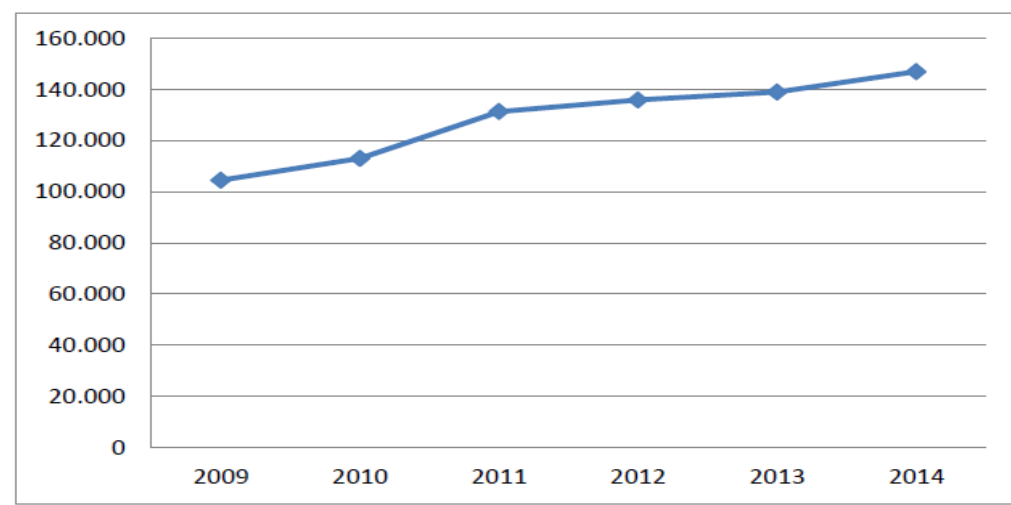

Figura 01. Evolução da frota no período entre 2009 - 2014

Fonte: Plano de Mobilidade Urbana de Presidente Prudente; 2014. 
Outro fator que se deve considerar é a quantidade de olarias para fabricação de telhas e tijolos que estão inseridas no Pontal do Paranapanema (BENTO MHS, 2012), o processo de fabricação de tijolos e telhas segue, essencialmente, as seguintes etapas: extração de argila, sazonamento, preparação da massa, conformação, secagem e a queima (CAMARA, 2015). Os principais poluentes atmosféricos emitidos são o material particulado (MP), o óxido de nitrogênio (NOX), o óxido de enxofre (SOX), o monóxido de carbono (CO), compostos clorados e fluoretados (DRUMM FC, 2014). A emissão de particulados ocorre tanto na manipulação e transporte da matéria-prima (emissões fugitivas) quanto pela queima nos fornos. Já a emissão dos gases ocorre devido à combustão e está vinculada à composição da matéria-prima e do combustível empregado. (BENTO MHS, 2012). O óxido de nitrogênio forma-se pela fixação térmica no nitrogênio atmosférico durante a queima, já o óxido de enxofre é proveniente principalmente da constituição da matéria-prima (mas também pode se originar do combustível, no caso do emprego de carvão ou óleos). O monóxido de carbono é formado tanto pela combustão incompleta como pela dissociação de carbonatos da argila. Já emissão de compostos halogenados depende majoritariamente da composição da matéria-prima usada (CAMARA, 2015).

A falta de locais apropriados para destinação dos resíduos sólidos ainda é um grave problema enfrentado pelo Pontal do Paranapanema. Dos 645 municípios paulistas, 27 dispõem os resíduos sólidos urbanos em condições inadequadas, com locais de destinação final apresentando problemas como a presença de vetores de doenças, emanação de odores, falta de controle operacional e outros. Os demais municípios, com exceção de três, que não foram avaliados por destinarem os resíduos fora do estado, dispõem os resíduos em condições adequadas (CETESB, 2015). O levantamento revela que Presidente Prudente é o município que se encontra em pior situação, alcançando 2,7 pontos numa escala que vai até 7,0 , a partir do qual as condições passam a ser consideradas adequadas. Pirapozinho, que se localiza na mesma região, também obteve baixa pontuação, com 2,8 (CETESB, 2015).

Apesar de proibida, a queima da cana ainda é realizada em algumas áreas do Pontal do Paranapanema, a queima provoca periodicamente a destruição e degradação de ecossistemas inteiros, tanto dentro como junto às lavouras canavieiras, além de dar origem a uma intensa poluição do ar, prejudicial à saúde, e que afeta não apenas as áreas rurais adjacentes, mas também os centros urbanos mais próximos, na queima da palha da cana são emitidos altos níveis de material particulado, monóxido de carbono, óxidos de nitrogênio, óxidos de enxofre e metano, que além de causarem danos à saúde das populações diretamente envolvidas (CARVALHO JUNIOR, 2013).

\section{REPERCUSSÕES NO SISTEMA RESPIRATÓRIO DE INDIVÍDUOS EXPOSTOS À POLUIÇÃO}

A rápida urbanização verificada em todo o planeta trouxe um grande aumento no consumo de energia e também de emissões de poluentes provenientes da queima de combustíveis fósseis por fontes fixas, como as indústrias, e por fontes móveis, como os veículos automotores (ARBEX, 2012).

Atualmente, aproximadamente $50 \%$ da população do planeta vivem em cidades e aglomerados urbanos e estão expostas a níveis progressivamente maiores de poluentes do ar. A outra metade, principalmente nos países em desenvolvimento, utiliza combustíveis sólidos derivados de biomassa (madeira, carvão vegetal, esterco animal seco e resíduos agrícolas) e combustíveis líquidos, em menor proporção, como fonte de energia para cocção, aquecimento e iluminação (BENTO MHS, 2012).

Devido à grande área de contato entre a superfície do sistema respiratório e o meio ambiente, a qualidade do ar interfere diretamente na saúde respiratória. Além disso, uma 
quantidade significante dos poluentes inalados atinge a circulação sistêmica através dos pulmões e pode causar efeitos deletérios em diversos órgãos e sistemas (ITO MS, 2013).

Para o Brasil, a Organização Mundial da Saúde estima que a poluição do ar possa causar cerca de $20 \mathrm{mil}$ óbitos/ano, valor cinco vezes superior ao número de óbitos estimado pelo tabagismo ambiental/passivo, e 10,7 mil óbitos/ano decorrentes da poluição do ar em ambientes internos (ITO JT, 2014).

Sob a denominação de material particulado (MP), se encontra uma classe de poluentes constituídos de poeiras, fumaças e todo o tipo de material sólido e líquido que, devido ao pequeno tamanho, mantém-se suspenso na atmosfera (DRUMM, 2014). As fontes destes poluentes vão desde as incômodas "fuligens" emitidas pelos veículos até as fumaças expelidas pelas chaminés industriais, passando pela poeira que se deposita nas ruas e é movimentada pelos veículos. A legislação brasileira preocupava-se, até 1989, apenas com as Partículas Totais em Suspensão (PTS), ou seja, todos os tipos e tamanhos de materiais sólidos ou líquidos que ficam suspensos no ar, na forma de poeira, neblina, aerossol, fumaça ou fuligem com uma faixa de tamanho menor que 100 $\mathrm{mm}$, causando efeitos significativos em pessoas com doença pulmonar, asma e bronquite (DRUMM, 2014). Pesquisas mostram que quanto menor o tamanho da partícula, maior o efeito sobre a saúde, ou seja, quanto mais fina a partícula, mais profunda ela penetra no aparelho respiratório. Desta forma, a partir de 1990, a legislação brasileira passou a também se preocupar com as Partículas Inaláveis (PI), menores que $10 \mathrm{~mm}$, originadas do processo de combustão industrial, de veículos automotores e do aerossol secundário (formado na atmosfera) (DRUMM, 2014). Partículas minúsculas como as emitidas por veículos, principalmente os movidos a diesel, podem ser menores do que a espessura de um fio de cabelo (BENTO, 2012).

$\mathrm{O}$ ar poluído é uma mistura de partículas - material particulado (MP) - e gases que são emitidos para a atmosfera principalmente por indústrias, veículos automotivos, termoelétricas, queima de biomassa e de combustíveis fósseis (ARBEX, 2012).

Diversos mecanismos têm sido sugeridos para explicar os efeitos adversos dos poluentes aéreos. A explicação mais consistente e mais aceita é a de que altas concentrações de oxidantes e pró-oxidantes contidos nos poluentes ambientais, como MP de diversos tamanhos e composição, e nos gases, como $\mathrm{O} 3$ e óxidos de nitrogênio, em contato com o epitélio respiratório, provocam a formação de radicais livres de oxigênio e de nitrogênio que, por sua vez, induzem o estresse oxidativo nas vias aéreas (BENTO MHS, 2012).

\section{CONCLUSÃO}

De acordo com o apresentado, observamos que a poluição atmosférica afeta diretamente a saúde respiratória de indivíduos expostos diretamente à poluição e o meio ambiente também sofre danos em seus sistemas principalmente em áreas mais próximas a emissão desses poluentes.

\section{REFERÊNCIAS}

Arbex MA, Santos UP, Martins LC, Saldiva PHN, Pereira LAA, Braga ALF. A poluição do ar e o sistema respiratório. J Bras Pneumol. 2012;38(5):643-655. https://doi.org/10.1590/S1806$\underline{37132012000500015}$

Bento MHS, Barreto PL, Godoy LP, Schmidt AS. Efeitos da poluição do ar causada por veículos automotores na saude humana e no meio ambiente. Revista de Engenharia e Tecnologia. 2012 Dez;4(3):19-34.

Camara VF, Lisboa HM, Hoinaski L, David PC. Levantamento das emissões atmosféricas da indústria da cerâmica vermelha no sul do .estado de Santa Catarina, Brasil. Cerâmica. 2015 Abr/Jun;61(358):213-218. https://doi.org/10.1590/0366-69132015613581872 
Carvalho Junior LCS, Ramos EMC, Toledo AC, Ceccato ADF, Macchione M, Braga ALF, Ramos D. Avaliação da qualidade de vida relacionada à saúde de cortadores de cana-de-açúcar nos períodos de entressafra e safra. Rev Saúde Pública. 2012 ;46(6):1058-65.

Companhia Ambiental do Estado de São Paulo: São Paulo; 2015 [Acesso em 2015 Out 06]. Disponivel em: http://www.cetesb.sp.gov.br/2015/05/18/cetesb-divulga-inventario-de-residuose-relatorios-anuais-de-qualidade-da-agua-do-ar-e-das-praias/

Conselho Nacional do Meio Ambiente (CONAMA, 2012). [Acesso em 2015 Out 06]. Disponível em: http://www.mma.gov.br/port/conama/res/res90/res0390.html

Cuisse RC. Efeitos da poluição atmosférica no sistema respiratório de individuos praticantes de exercício físico aeróbico em ambiente aberto e fechado [dissertação]. Presidente Prudente: Universidade Estadual Paulista Faculdade de Ciências e Tecnologia; 2014.

Drumm FC, Gerhardt AE, Fernandes GD, Chagas P, Sucolotti MS, Kemerich PDC. Poluição atmosférica proveniente da queima de combustíveis derivados do petróleo em veículos automotores. REGET.2014 Abr;18(1):66-78. https://doi.org/10.5902/2236117010537.

Ferreira AD. Efeitos dos poluentes gerados pela queima de biomassa no transporte mucociliar nasal e percepção da qualidade de vida de cortadores de cana [dissertação]. Presidente Prudente: Universidade Estadual Paulista Faculdade de Ciências e Tecnologia; 2011.

Ito JT. Efeito agudo do fumo na variabilidade da frequência cardiáca e da sua cessação no transporte mucociliar [dissertação]. Presidente Prudente: Universidade Estadual Paulista Faculdade de Ciências e Tecnologia; 2014.

Organização Mudial de Saúde, 2009 [Acesso em 2015 Out 06]. Disponível em: \{http://www.jornaldepneumologia.com.br/detalhe_artigo.asp? id=79\}

Plano de Mobilidade urbana de Presidente Prudente. Presidente Prudente; 2014. 